\title{
Gastrointestinal digeneans (Platyhelminthes: Trematoda) of horseshoe and vesper bats (Chiroptera: Rhinolophidae and Vespertilionidae) in Serbia
}

\author{
Ž. HORVAT ${ }^{1}$, B. ČABRILO ${ }^{2 *}$, M. PAUNOVIĆ ${ }^{3}$, B. KARAPANDŽA ${ }^{4}$, J. JOVANOVIĆ3 ${ }^{3}$ I. BUDINSKI ${ }^{5}$, O. BJELIĆ ČABRILO²
}

\begin{abstract}
${ }^{1}$ Agricultural school, Subotički put bb, Bačka Topola, Serbia, cibi@stcable.net; ${ }^{2}$ University of Novi Sad, Faculty of Sciences, Department of Biology and Ecology, Trg Dositeja Obradovića 3, Novi Sad, Serbia, " ${ }^{*}$ borislav.cabrilo@dbe.uns.ac.rs, olivera.bjelic-cabrilo@dbe.uns.ac.rs; ${ }^{3}$ Natural History Museum, Njegoševa 51, Belgrade, Serbia, milan.paunovic@nhmbeo.rs, jelena.jovanovic@nhmbeo.rs; ${ }^{4}$ Fauna C\&M, Zemunska 19, Novi Banovci, Serbia, fauna.cm@gmail.com; ${ }^{5}$ Department of Genetic Research, Institute for Biological Research "Siniša Stanković", University of Belgrade, Bulevar despota Stefana 142, 11060 Belgrade, Serbia, ivana.budinski@ibiss.bg.ac.rs
\end{abstract}

Article info

Received May 25, 2016

Accepted November 7, 2016

\begin{abstract}
Summary
The qualitative and quantitative analyses of the digenean fauna of bats were conducted for the first time in Serbia. The sample comprised of 118 individuals of 12 bat species (Rhinolophus ferrumequinum, Myotis mystacinus, M. alcathoe, M. brandtii, M. oxygnathus, M. myotis, Hypsugo savii, Pipistrellus pipistrellus, $P$. nathusii, Plecotus auritus, $P$. austriacus and Nyctalus noctula) collected from 15 sites throughout Serbia. Six digenean species were identified: Lecithodendrium linstowi, Plagiorchis sp., Prosthodendrium longiforme, $P$. chilostomum, $P$. parvouterus and Mesotretes peregrinus. The helminths were recorded from 35 individual hosts $(29.7 \%)$. The species Lecithodendrium linstowi infected the highest percentage of hosts (19.5\%), with a mean abundance of 4.6. GLM analysis of exploratory factors showed that host species and host sex had a significant influence on parasite load, while locality and host age did not influence parasite abundance. No evidence of zoonotic species was found.
\end{abstract}

Keywords: digeneans; bats; Serbia; prevalence; abundance

\section{Introduction}

The mammalian order Chiroptera is highly diverse, with more than 1300 species of bats currently described (Fenton \& Simmons, 2014). Owing to their capability for active flight and echolocation, their distribution is ubiquitous (Jones \& Teeling, 2006). Bats are important members of all types of terrestrial ecosystems, acting as reliable indicators of the condition and health of the environment (Paunović et al., 2011).

The helminth fauna of bats has been the subject of numerous studies throughout Europe (Chiriac \& Barbu, 1973; Esteban et al., 1991, 2001; Botella et al., 1993; Ricci, 1995; Demidova \& Vekhnik, 2004; Kirillov et al., 2012; Shimalov et al., 2011; Lord et al., 2012; Kluwak et al., 2013). Digeneans are often the dominant helminth category in the gastrointestinal tract of bats (Esteban et al., 2001; Botella et al., 1993; Ricci, 1995; Kluwak et al., 2013; Lotz \& Font,
1991). A possible explanation is that most studies focused on insectivorous species, with the composition of the helminth fauna determined by life style, habitat use, diet and type of prey. The life cycle of digeneans, aside from the bat which is the definitive host, includes 2 intermediate hosts: mollusks and insects. Metacercaria of certain digeneans develop inside aquatic insects which, upon metamorphosis into the adult stage, can be preyed upon by bats that favor wetland and aquatic habitats (Hall, 1960; Macy, 1960). To date, studies of bats in Serbia primarily concentrated on their biology and ecology (Paunović, 1998, 2004; Paunović et al., 2003, 2011). Within the former Yugoslavia, data on the helminths of this mammal order were reported from the territories of Croatia and Slovenia (Barus \& Daniel, 1972; Vaucher, 1975; Brglez \& Bidovec, 1987). The first report of the helminth fauna of bats in Serbia was only recently published (Horvat et al., 2015). The purpose of the present study was to help supplement information on the digenean

\footnotetext{
$\bar{*}$ - corresponding author
} 
parasites of a selection of rhinolophid and vespertilionid bat species living in Serbia.

\section{Material and Methods}

One hundred and eighteen bats belonging to 12 different species were subjected to helminthological analysis. The species included were the greater horseshoe bat (Rhinolophus ferrumequinum 16 individuals), whiskered bat (Myotis mystacinus - 4), Alcathoe whiskered bat $(M$. alcathoe -3$)$, Brandt's bat $(M$. brandtii -2$)$, lesser mouse-eared bat (M. oxygnathus - 26), greater mouseeared bat (M. myotis - 28), Savi's pipistrelle (Hypsugo savii - 10), common pipistrelle (Pipistrellus pipistrellus - 3), Nathusius' pipistrelle ( $P$. nathusii - 3), brown long-eared bat (Plecotus auritus - 9), grey long-eared bat ( $P$. austriacus -4$)$ and common noctule
(Nyctalus noctula - 10). These bats were collected from 15 sites throughout Serbia: Deliblato sands, Zasavica, Valjevo, Belgrade, Paraćin, Đerdap, Bor, Beljanica, Kučevo, Boljevac, Zaječar, Zlot, Medveđa, Tara mountain and Ivanjica (Fig. 1, Table 1).

Capture and examination of bats was always conducted with the required licenses granted by the Ministry responsible for environmental protection, in accordance with national legislation. Individuals collected for various purposes and deposited in the Study Mammal Collection of the Natural History Museum in Belgrade were used in this study (Table 2). Bats were captured using mist-nets and harp-traps at the entrances of or inside their roost sites. Mist-nets were also used in different types of habitat. Individual bats were caught by hands from walls and ceilings of their roost sites. Additionally, injured bats from the Belgrade area were brought in by citizens for rehabilitation, and the ones that died or

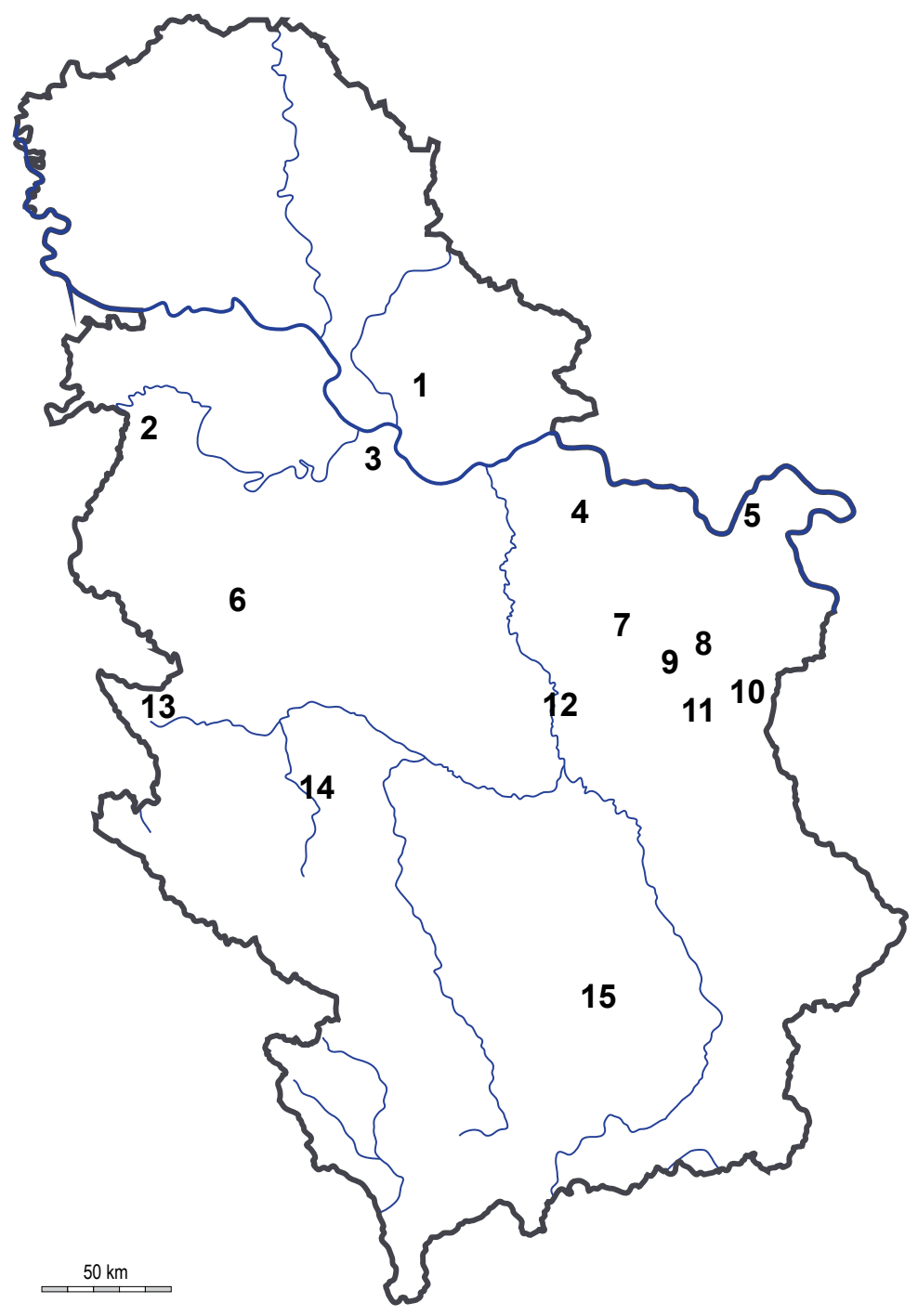

Fig. 1. A map of Serbia highlighting the sites of bat collection. Localities follow numbers given in Table 1. 
Table 1. List of bat species (number of individuals in brackets after species name) collected from 15 localities in Serbia with dates of collection. Numbers in brackets after each locality indicate its position on Fig. 1.

\begin{tabular}{|c|c|c|}
\hline Locality & Bat species & Collection date \\
\hline \multirow{2}{*}{ Deliblato sands (1) } & R. ferrumequinum (2) & August 2007, April 2009 \\
\hline & P. auritus (3) & June $2006^{*}$ \\
\hline \multirow{3}{*}{ Zasavica (2) } & R. ferrumequinum (1) & August 2006 \\
\hline & M. alcathoe (1) & July 2007 \\
\hline & P. nathusii (1) & April 2006 \\
\hline \multirow{2}{*}{ NHM Belgrade (3) } & H. savii (7) & July 2005, September 2008*, July 2009 \\
\hline & P. nathusii (2) & October 2008, January 2009 \\
\hline Kučevo (4) & R. ferrumequinum (3) & NA \\
\hline Đerdap (5) & R. ferrumequinum (2) & July 2005 \\
\hline \multirow{6}{*}{ Valjevo (6) } & R. ferrumequinum (2) & May 2003, April 2009 \\
\hline & M. oxygnathus (11) & May 2006, August 2008 \\
\hline & M. myotis (12) & May 2006, August 2008 \\
\hline & H. savii (2) & August 2008 \\
\hline & P. auritus (3) & May 2002, May 2008 \\
\hline & P. austriacus (4) & May 2002, July 2006, May 2008 \\
\hline \multirow{3}{*}{ Beljanica (7) } & R. ferrumequinum (2) & \\
\hline & M. oxygnathus (1) & July 2004 \\
\hline & P. auritus (1) & \\
\hline \multirow{4}{*}{ Bor (8) } & R. ferrumequinum (3) & November 2003, July 2007 \\
\hline & M. oxygnathus (2) & November 2003, November 2008 \\
\hline & H. savii (1) & August 2004 \\
\hline & P. pipistrellus (3) & November 2002, July 2007 \\
\hline \multirow{2}{*}{ Zlot (9) } & M. oxygnathus (1) & July 2006 \\
\hline & M. myotis (1) & July 2007 \\
\hline \multirow{2}{*}{ Zaječar (10) } & M. oxygnathus (2) & \multirow{2}{*}{ May 2008} \\
\hline & M. myotis (2) & \\
\hline \multirow{5}{*}{ Boljevac (11) } & R. ferrumequinum (1) & October 2007 \\
\hline & M. mystacinus (1) & July 2008 \\
\hline & M. brandtii (1) & August 2008 \\
\hline & M. myotis (2) & October 2006 \\
\hline & P. auritus (1) & 2008 \\
\hline \multirow{2}{*}{ Paraćin (12) } & M. mystacinus (3) & \multirow{2}{*}{ August 2008} \\
\hline & M. alcathoe (2) & \\
\hline \multirow{2}{*}{ Tara mountain (13) } & M. brandtii (1) & July 2007 \\
\hline & P. auritus (1) & July 2006 \\
\hline \multirow{2}{*}{ Ivanjica (14) } & M. oxygnathus (9) & \multirow{2}{*}{ September 2008} \\
\hline & M. myotis (11) & \\
\hline Medveđa (15) & N. noctula (10) & September 2002 \\
\hline
\end{tabular}

* Month and year of collection unknown for certain individual bats 
were euthanized were also used in this study; their locality is given as "NHM Belgrade" in Table 1. Bat species were identified according to standard literature (Dietz et al., 2009), as well as through comparison with specimens in the Study Mammal Collection of the Natural History Museum in Belgrade. Dissection of the bats was done by standard procedure in the laboratory and the taxidermy workshop of the Natural History Museum. Gastrointestinal tracts were extracted and frozen at $-18^{\circ} \mathrm{C}$.

Digeneans were collected from previously frozen gastrointestinal tracts and preserved in $70 \%$ ethanol. After this, they were kept in distilled water for 24 hours in order to wash out the alcohol.
They were then stained with borax carmine and dehydrated in a series of ethanol solutions of growing concentration (15 minutes in $70 \%, 80 \%$ and $90 \%$ solutions and 5 minutes in $96 \%$ solution). After dehydration, the parasites were cleared in cedar wood oil for 24 hours, after which they were mounted in Canada balsam as permanent microscope slides (cited from Vojtkova, 1974). Digeneans were identified according to an identification key (Bray et al., 2008) and data from literature (Matskási 1967, 1968; Esteban et al., 1999). Sampled bat specimens are kept in the Study Mammal Collection of the Natural History Museum in Belgrade, Serbia. The collected digeneans are stored in the zoological collection of

Table 2. Accession numbers of bat specimens deposited in the collection of the NHM in Belgrade used in this study.

\begin{tabular}{|c|c|c|c|}
\hline Accession nos. & & Species & Collection date \\
\hline $353-354 /$ & 02 & P. austriacus & May 2002 \\
\hline $410-411 /$ & 02 & P. pipistrellus & November 2002 \\
\hline $06 /$ & 03 & M. myotis & September 2008 \\
\hline $37-41 /$ & 03 & \multirow{2}{*}{ N. noctula } & \multirow{2}{*}{ September 2002} \\
\hline $44-48 /$ & 03 & & \\
\hline $144 /$ & 03 & R. ferrumequinum & May 2003 \\
\hline $24 /$ & 04 & M. oxygnathus & July 2004 \\
\hline $33-34 /$ & 04 & R. ferrumequinum & July 2004 \\
\hline $41 /$ & 04 & $P$. auritus & July 2004 \\
\hline $85 /$ & 04 & H. savii & August 2004 \\
\hline $106 /$ & 04 & $P$. auritus & May 2002 \\
\hline $73-75 /$ & 05 & R. ferrumequinum & NA \\
\hline $88-89 /$ & 05 & H. savii & July 2005 \\
\hline $90 /$ & 05 & \multirow{2}{*}{ R. ferrumequinum } & \multirow{2}{*}{ July 2005} \\
\hline $98 /$ & 05 & & \\
\hline $114 /$ & 05 & R. ferrumequinum & November 2003 \\
\hline $116 /$ & 05 & M. oxygnathus & November 2003 \\
\hline $08-09 /$ & 06 & $P$. auritus & June 2006 \\
\hline $10 /$ & 06 & R. ferrumequinum & August 2006 \\
\hline $15 /$ & 06 & P. nathusii & April 2006 \\
\hline $19 /$ & 06 & M. oxygnathus & July 2006 \\
\hline $22-23 /$ & 06 & M. myotis & October 2006 \\
\hline $01 /$ & 07 & R. ferrumequinum & August 2007 \\
\hline $27 /$ & 07 & M. alcathoe & \multirow{2}{*}{ July 2007} \\
\hline $28 /$ & 07 & R. ferrumequinum & \\
\hline $38 /$ & 07 & $P$. pipistrellus & \multirow{2}{*}{ July 2007} \\
\hline $39 /$ & 07 & R. ferrumequinum & \\
\hline $48 /$ & 07 & M. myotis & July 2007 \\
\hline $54 /$ & 07 & $P$. auritus & NA \\
\hline $85 /$ & 07 & R. ferrumequinum & October 2007 \\
\hline $23 /$ & 08 & P. austriacus & May 2008 \\
\hline $24-25 /$ & 08 & P. auritus & May 2008 \\
\hline
\end{tabular}




\begin{tabular}{|c|c|c|c|}
\hline $28 /$ & 08 & M. brandtii & July 2007 \\
\hline $34 /$ & 08 & $P$. auritus & July 2006 \\
\hline $54 /$ & 08 & P. austriacus & July 2006 \\
\hline $61 /$ & 08 & M. mystacinus & July 2008 \\
\hline $91 /$ & 08 & H. savii & September 2008 \\
\hline $106 /$ & 08 & P. nathusii & October 2008 \\
\hline $110-112 /$ & 08 & M. myotis & \multirow{5}{*}{ September 2008} \\
\hline $113-120 /$ & 08 & M. oxygnathus & \\
\hline $121-122 /$ & 08 & M. myotis & \\
\hline $123 /$ & 08 & M. oxygnathus & \\
\hline $124-128 /$ & 08 & M. myotis & \\
\hline $131 /$ & 08 & M. oxygnathus & November 2008 \\
\hline $132 /$ & 08 & M. brandtii & August 2008 \\
\hline $133-134$ & 08 & H. savii & 2008 \\
\hline $165 /$ & 08 & $P$. auritus & \multirow{5}{*}{ August $2008^{*}$} \\
\hline $166-167 \mid$ & 08 & M. oxygnathus & \\
\hline $168 /$ & 08 & H. savii & \\
\hline $169 /$ & 08 & M. myotis & \\
\hline $170 /$ & 08 & H. savii & \\
\hline $178 /$ & 08 & H. savii & July 2009 \\
\hline $181 /$ & 08 & M. alcathoe & \multirow{3}{*}{ August 2008} \\
\hline $182-184 /$ & 08 & M. mystacinus & \\
\hline $185 /$ & 08 & M. alcathoe & \\
\hline $230 /$ & 08 & M. oxygnathus & \multirow{2}{*}{ May 2006} \\
\hline $231 /$ & 08 & M. myotis & \\
\hline $233 /$ & 08 & M. oxygnathus & \multirow{6}{*}{ May 2006} \\
\hline $234-237 /$ & 08 & M. myotis & \\
\hline $238 /$ & 08 & M. oxygnathus & \\
\hline $239 /$ & 08 & M. myotis & \\
\hline $240 /$ & 08 & M. oxygnathus & \\
\hline $241 /$ & 08 & M. myotis & \\
\hline $243 /$ & 08 & M. oxygnathus & \multirow{3}{*}{ May 2006} \\
\hline $244-247 /$ & 08 & M. myotis & \\
\hline $248 /$ & 08 & M. oxygnathus & \\
\hline $250-252 /$ & 08 & M. oxygnathus & May 2006 \\
\hline $01 /$ & 09 & P. nathusii & January 2009 \\
\hline $05 /$ & 09 & \multirow{2}{*}{ R. ferrumequinum } & \multirow{2}{*}{ April 2009} \\
\hline $07 /$ & 09 & & \\
\hline $41 /$ & 09 & H. savii & July 2009 \\
\hline $44 /$ & 09 & M. myotis & May 2008 \\
\hline $60 /$ & 09 & M. oxygnathus & May 2008 \\
\hline $70 /$ & 09 & M. myotis & May 2008 \\
\hline $71 /$ & 09 & M. oxygnathus & May 2008 \\
\hline
\end{tabular}

${ }^{*}$ Month of collection unknown for certain bats 
Table 3. Quantitative parameters of digenean infection of bats in Serbia.

\begin{tabular}{lcccccccc}
\hline Species & $\mathrm{n}$ & $\mathrm{N}$ & $\mathrm{P}(\%)$ & $\mathrm{MA}$ & $\min$ & $\max$ & $\sigma$ & $\mathrm{CV}(\%)$ \\
\hline Plagiorchis sp. & 15 & 166 & 12.7 & 1.4 & 1 & 41 & 11 & 99.4 \\
Lecithodendrium linstowi & 23 & 546 & 19.5 & 4.6 & 1 & 202 & 46 & 194 \\
Prosthodendrium longiforme & 4 & 20 & 3.4 & 0.2 & 2 & 8 & 2.6 & 51.6 \\
P. chilostomum & 4 & 41 & 3.4 & 0.4 & 1 & 23 & 9.4 & 92 \\
P. parvouterus & 2 & 8 & 1.7 & 0.1 & 1 & 7 & 4.2 & 106 \\
Mesotretes peregrinus & 2 & 2 & 1.7 & 0.02 & 1 & 1 & & \\
\hline Total & 35 & 783 & & & & &
\end{tabular}

$\mathrm{n}$ - number of infected host specimens, $\mathrm{N}$ - number of parasite individuals, $\mathrm{P}(\%)$ - prevalence, $\mathrm{MA}$ - mean abundance, min - minimum number of parasite individuals, max - maximum number of parasite individuals, $\sigma$ - standard deviation, $\mathrm{CV}(\%)$ - coefficient of variation

the Department of Biology and Ecology at the Faculty of Sciences in Novi Sad, Serbia. The digenean species accession numbers are as follows: Plagiorchis sp. (OBZS2012.0001-0166), L. linstowi (OBZS2012.0167-0712), P. longiforme (OBZS2012.07130732), P. chilostomum (OBZS2012.0733-0774), P. parvouterus (OBZS2012.0774-0781), M. peregrinus (OBZS2012.0782-0783).

Prevalence and mean abundance were calculated for all parasite species (Bush et al., 1997) in Quantitative Parasitology 3.0 software (Rózsa et al., 2000). Abundance data was fitted to a generalized linear model (GLM), with host species, locality, host sex and host age (juvenile or adult), as well as their two-way interactions, used as terms predicting the numerical response. The models were eliminated in a stepwise fashion until the most satisfactory minimal model explaining the variation in abundance was obtained. Abundances were analyzed for each digenean species separately, as well as for total digenean load. Certain species of bats $(M$. brandtii, $M$. mystacinus, $N$. noctula) were represented by only one sex. Following GLM, differences in abundance data among different species of hosts were tested by Tukey's post hoc test. Calculations were performed in $\mathrm{R}$ software ( $\mathrm{R}$ Core Team, 2015) using standard and MULTCOMP 1.4-6 (Hothorn et al., 2008) packages.

\section{Results}

Of the 118 examined host individuals, 35 were infected with digeneans, resulting in a prevalence of $29.7 \%$. A total of 783 parasites were collected, belonging to six species (Table 3). Four species were only found in the intestine: Prosthodendrium longiforme (Bhalerao, 1926), P. chilostomum (Mehlis, 1831), P. parvouterus (Bhalerao, 1926) and Mesotretes peregrinus (Braun, 1900). Lecithodendrium linstowi (Dollfus, 1931) was found in the intestine and stomach, and Plagiorchis sp. was recovered from the intestine and rectum.

Four digenean species were found in 4 host species ( $M$. myotis, H. savii, P. auritus and N. noctula) (Table 4). In P. pipistrellus only 1 digenean species was recorded, and none were found in M. oxygnathus. The most widespread digeneans were $L$. linstowi, found in 10 host species, and Plagiorchis sp. found in 9. Prosthodendrium parvouterus was found only in $P$. auritus, with the remaining digeneans present in 2 or 4 host species (Table 4). Lecithodendrium linstowi was also dominant with regards to quantitative parameters. It infected the highest number of hosts (23) and was most abundant in the sample (546 individuals), resulting in highest prevalence and mean abundance values (Table 3 ).

The minimum number of parasite individuals collected from a single host was 1 for five of six of the documented digenean species. The intensity ranged from 1 to 202 . The latter was the number of $L$. linstowi individuals in 1 infected individual of $P$. nathusii. The highest coefficient of variation of parasite number per individual host was noted for the very same digenean species (194\%) (Table 3). Since the number of Myotis bats collected in this study permitted a more thorough analysis, primary infection parameters were calculated on the genus level. Total prevalence of infection was $19 \%$, with $L$. linstowi as the most prevalent species. Parasite load was also highest for this digenean species, as seen in its mean intensity and abundance values. Of the 6 parasite species noted in this study, only P. parvouterus was absent in Myotis bats. However, L. linstowi, which was the most common parasite in this study, was absent in M. myotis, the most numerous host in the sample (Table 5).

Of the 35 infected bats, the majority $(65.7 \%)$ carried only a single digenean species. A smaller percentage of infected hosts carried $2(25.7 \%)$ and $3(8.6 \%)$ different digenean species. When 2 digeneans occurred together, the most common association was that between the most common parasites, L. linstowi and Plagiorchis sp. Co-occurrences of 3 digenean species were noted in 3 infected bats, each one hosting a different combination of parasites.

The small sample size and scattered distribution of the four rarest digenean species ( $P$. longiforme, $P$. chilostomum, $P$. parvouterus and $M$. peregrinus) precluded a meaningful analysis of abundance data: none of the factors used in the GLM could explain the variation in their abundance. On the other hand, results obtained for Plagiorchis sp. and Lecithodendrium linstowi, as well as the pooled digenean sample, were remarkably consistent, with host species and its interaction with host sex significantly influencing parasite load ( $p<0.0001$ for factor "host" and the interaction "host:sex" in all three data subsets). An independent effect of sex was also noted 
Table 4. Digenean species of bats in Serbia and their occurrence in different host species. Number of individuals of each host species is given in brackets.

\begin{tabular}{|c|c|c|c|c|c|c|c|c|c|c|c|c|c|}
\hline \multirow[b]{2}{*}{ Digenean species } & \multicolumn{12}{|c|}{ Hosts } & \multirow[b]{2}{*}{$n_{h}$} \\
\hline & $\begin{array}{l}\text { Rhf } \\
(16)\end{array}$ & $\begin{array}{c}\text { Mmy } \\
(4)\end{array}$ & $\begin{array}{c}\text { Mal } \\
(3)\end{array}$ & $\begin{array}{c}M b r \\
(2)\end{array}$ & $\begin{array}{l}\text { Mox } \\
\text { (26) }\end{array}$ & $\begin{array}{l}M m \\
(28)\end{array}$ & $\begin{array}{l}H s \\
(10)\end{array}$ & $P p(3)$ & $\operatorname{Pn}(3)$ & $\begin{array}{l}\text { Paur } \\
\text { (9) }\end{array}$ & $\begin{array}{c}\text { Paus } \\
\text { (4) }\end{array}$ & $\begin{array}{l}N n \\
(10)\end{array}$ & \\
\hline Plagiorchis sp. & + & + & - & + & - & + & + & - & + & + & + & + & 9 \\
\hline Lecithodendrium linstowi & + & + & + & + & - & - & + & + & + & + & + & + & 10 \\
\hline $\begin{array}{l}\text { Prosthodendrium } \\
\text { longiforme }\end{array}$ & + & - & + & - & - & + & - & - & - & - & - & + & 4 \\
\hline P. chilostomum & - & - & - & - & - & + & + & - & - & + & - & + & 4 \\
\hline P. parvouterus & - & - & - & - & - & - & - & - & - & + & - & - & 1 \\
\hline Mesotretes peregrinus & - & - & - & - & - & + & + & - & - & - & - & - & 2 \\
\hline $\mathrm{n}_{\mathrm{d}}$ & 3 & 2 & 2 & 2 & 0 & 4 & 4 & 1 & 2 & 4 & 2 & 4 & \\
\hline
\end{tabular}

$\mathrm{n}_{\mathrm{d}}$ - number of digenean species per host species of bat, $\mathrm{n}_{\mathrm{h}}$ - number of bat host species of each digenean, Rhf - Rhinolophus ferrumequinum, Mmy - Myotis mystacinus, Mal - M. alcathoe, Mbr - M. brandtii, Mox - M. oxygnathus, Mm - M. myotis, Hs - Hypsugo savii, Pp - Pipistrellus pipistrellus, Pn - P. nathusii, Paur - Plecotus auritus, Paus - P. austriacus, Nn - Nyctalus noctula

for $L$. linstowi $(\mathrm{p}=0.0059)$ and digeneans in total $(\mathrm{p}=0.0004)$. Abundance of Plagiorchis sp., L. linstowi and digeneans in general was higher in $P$. nathusii, compared to the other bats analyzed. When sex significantly affected parasite abundance, females were more infected, although infection prevalence was greater in male bats. The host species - host sex interaction was detected due to the fact that, in $P$. nathusii, the only infected individual was a female carrying 243 individual parasites. Locality and host age did not influence the abundance of digeneans.

\section{Discussion}

This study is an initial analysis of qualitative and quantitative structure of the digenean fauna of bats in Serbia. The 6 digenean species registered in the sample were $L$. linstowi, Plagiorchis sp., $M$. peregrinus, $P$. chilostomum, P. parvouterus and $P$. longiforme. The life cycles of the majority of these digeneans are still unknown, beyond the fact that intermediate hosts are necessary for their development. Differences in the qualitative and quantitative structure of the digenean fauna of the examined bat species may be due to their preference for specific prey items that represent potential intermediate hosts. According to data from the literature, digeneans are frequently encountered in bat populations as a consequence of the insectivorous diet of the bat hosts (Lord et al., 2012). All of the six digenean species recorded in this study were previously found in bats in various countries of Europe (Matskási, 1967, 1968, 1975; Kochseder, 1969; Chiriac \& Barbu, 1973; Esteban et al., 1990, 1991, 1999, 2001; Ricci, 1995; Botella et al., 2003; Demidova \& Vekhnik, 2004; Kirillova et al., 2007; Shimalov et al., 2011; Lord et al., 2012; Kluwak et al., 2013).

Of the 12 bat species included in this study, only M. oxygnathus was found to be uninfected with digenean parasites. Data from neighboring Hungary (Matskási, 1967, 1968), for example, contrasts this find. The absence of digeneans in this bat species in the current study cannot be attributed to any of the studied factors, since the M. oxygnathus sample contained both males and females, juveniles and adults, and bats collected from six different localities. With regards to factors affecting parasite abundance, it should also be noted that the abundances of the 4 rarest parasite species could not be fitted to any model. In order to address this issue, as well as the apparent absence of digeneans in M. oxygnathus in Serbia, further studies are necessary.

Abundance of digeneans in general, as well as that of $L$. linstowi, was found to be influenced by host sex as an independent factor; specifically, female bats on average carried more parasites. Sex-biased parasitism is still relatively poorly understood, in spite of more than a century of research (Zuk \& McKean, 1996). A study of the big brown bat (Eptesicus fuscus) in the USA found that

Table 5. Primary infection parameters for bats of the genus Myotis $(\mathrm{n}=63)$.

\begin{tabular}{cccccc}
\hline Species & $\mathrm{n}$ & $\mathrm{N}$ & $\mathrm{P} \%$ & $\mathrm{MA}$ & $\mathrm{Ml}$ \\
\hline Plagiorchis sp. & 3 & 11 & 4.8 & 0.2 & 3.7 \\
L. linstowi & 5 & 94 & 7.9 & 1.5 & 18.8 \\
P. longiforme & 2 & 6 & 3.2 & 0.1 & 3 \\
P. chilostomum & 1 & 1 & 1.6 & 0.02 & 1 \\
M. peregrinus & 1 & 1 & 1.6 & 0.02 & 1 \\
Total & 12 & 113 & 19 & 1.8 & 9.4 \\
\hline n- number of infected host specimens, N- number of parasite individuals, P(\%)- prevalence, MA-mean abundance Ml - mean intensity
\end{tabular}


parasite burdens and host immunity are better predicted by host body condition, rather than host sex, with animals in better condition capable of activating more facets of their immune response in order to challenge parasite infections (Warburton et al., 2016). The difference in male and female parasite loads in this study may thus simply be an artifact of underlying differences in body condition, and resources available for immune defense. However, sex-biased parasitism is a highly complex phenomenon, and an intricate web of intertwining factors determines its scope and direction (Krasnov et al., 2012). Further studies of this type in Serbia may help to elucidate patterns of sex biases in parasite infection in bat hosts. Host identity also influenced parasite abundance, with $P$. nathusii more heavily infected than the other studied species. However, only three specimens of this species were analyzed, and one of them was the most heavily infected animal in the sample. Analysis of infection parameters in the genus Myotis revealed that the most frequent parasite was $L$. linstowi, but this digenean was conspicuously absent in $M$. oxygnathus and $M$. myotis. The absence of $L$. linstowi in these Myotis species is likely explained by their diet. Metacercaria of digeneans from the family Lecithodendriidae often develop in the body of larvae and nymphs of aquatic insects of the order Plecoptera, Ephemeroptera, Odonata or Trichoptera (Hall, 1960), whereas the main prey items of $M$. oxygnathus and M. myotis are coleopterans (Carabidae, Scarabaeidae, Silphidae), orthopterans (Tettigoniidae, Gryllotalpidae), dermapterans and hymenopterans (Arlettaz, 1996; Pereira et al., 2002; Siemers et al., 2011; Graclik \& Wasielewski, 2012).

Studies on the composition of the helminth fauna of wild animals can reveal the presence of parasites that are potential pathogens of domestic animals or man. This study found no evidence of the presence of zoonotic species in bats in Serbia. However, the six digeneans noted here may represent only a fraction of the total number of species parasitizing bats in Serbia, emphasizing the necessity for further research.

In conclusion, our survey of intestinal digeneans of bats in Serbia revealed the presence of six species that are commonly found in European chiropterans. Analysis of abundance data showed a marked influence of host identity and sex, whereas host age and locality played no part in determining parasite load. Certain finds were somewhat unexpected: the absence of $L$. linstowi in M. myotis, and the absence of digeneans altogether in $M$. oxygnathus, requiring deeper consideration of the subject. This study provides a basis for more thorough research of endoparasites of bats in Serbia, and hopefully represents a starting point for further studies on this topic.

\section{References}

Álvarez, F., Rey, J., Quinterios, P., Iglesias, R., Santos, M., SanmarTIN, M.L. (1991): Helminth parasites in some Spanish bats. Ann. Parasitol., 37 (3): 321 - 329

ArLetTAZ, R. (1996): Feeding behaviour and foraging strategy of free-living mouse-eared bats, Myotis myotis and Myotis blythii.
Anim. Behav., 51 (1): 1 - 11. DOI: 10.1006/anbe.1996.0001

Barus, V., Daniel, M. (1972): The occurrence of some helminth species in birds and mammals from Yugoslavia. Folia Parasitol., 19 (2): $111-112$

Botella, P., Sanchez, L., Esteban, J.G. (1993): Helminthfauna of bats in Spain. III Parasites of Pipistrellus pipistrellus (Schreber, 1774) (Chiroptera: Vespertilionidae). Res. Rev. Parasitol., 53 (1 $-2): 63-70$

Bray, R.A., Gibson, D.I., Jones, A. (2008): Keys to the Trematoda vol. 3. London, CABI Publishing, Wallingford, UK and the Natural History Museum, $824 \mathrm{p}$.

BRglez, J., Bidovec, A. (1987): Three species of Trichostrongylidae, Leiper 1912, in some wild animals in Slovenia. Zbornik Veterinarstvo, 24 (2): $167-172$

Bush, A.O., Lafferty, K.D., LotZ, J.M., Shostak, A.W. (1998): Parasitology meets ecology on its own terms: Margolis et al. revisited. J. Parasitol., 83: 575 - 583. DOI: 10.2307/3284227

ChIRIAC, E., Barbu, P. (1973): Comparative study of the helminth parasites of Chiroptera in Roumania. An. Univ. Bucur. Biol., 22: $19-24$

Demidova, T.N., VeKHNIK, V.P. (2004): Trematodes (Trematoda, Monorchiidae) of Myotis brandtii and M. mystacinus (Chiroptera, Vespertilionidae) in Samarskaya Luka (Russia). Vestn. Zool., 38 (5): $71-74$

Dietz, C., von Helversen, O., Nill, D. (2009): Bats of Britain, Europe and Northwest Africa. London, A \& C Black Publishers Ltd, $400 \mathrm{p}$. Esteban, J.G., Amengual, B., Сobo, J.S. (2001): Composition and structure of helminth communities in two population of Pipistrellus pipistrellus (Chiroptera: Vespertilionidae) from Spain. Folia Parasitol., 48: 143 - 148. DOI: 10.14411/fp.2001.022

Esteban, J.G., Botella, P., Toledo, R., Oltra-Ferrero, J.L. (1999): Helminthfauna of bats in Spain IV. Parasites of Rhinolophus ferrumequinum (Schreber, 1774) (Chiroptera: Rhinolophidae). Res. Rev. Parasitol., 59 (1 - 2): 57 - 68

Esteban, J.G., Oltra-Ferrero, J.L., Mas-Coma, S. (1990): Helminthfauna of bats in Spain. II. Parasites of Miniopterus schreibersii (Kuhl, 1819) (Chiroptera: Vespertilionidae). Rev. Iber. Parasitol., 50 (3 - 4): 199 - 209

Esteban, J.G., Oltra-Ferrero, J.L., Mas-Coma, S. (1991): Helminths of bats in Spain: faunistic spectrum and applied study. In: Benzal, J., DE Paz, O. (Eds). Los murciélagos de España y Portugal. Madrid, ICONA, Colleción Técnica, pp. 281 - 304. DOI: 10.1111/j.1365-2907.1992.tb00130.x

Fenton, M.B., Simmons, N.B. (2014): Bats: a world of science and mystery. Chicago, The University of Chicago Press, 303p. DOI: 10.7208/chicago/9780226065267.001.0001

GracliK, A., WasIeleWSKI, O. (2012): Diet composition of Myotis myotis (Chiroptera, Vespertilionidae) in western Poland: results of fecal analyses. Turk. J. Zool., 36 (2): 209 - 213

HALL, J.E. (1960): Some lecithodendriid metacercariae from Indiana and Michigan. J. Parasitol., 46(3), 309 - 314. DOI: $10.2307 / 3275492$ 
Horvat, Ž., Čabrilo, B., Paunović, M., Karapandža, B., Jovanović, J., BUDINSKI, I., BJELIĆ-ČABRILO, O. (2015): The helminth fauna of the greater horseshoe bat (Rhinolophus ferrumequinum) (Chiroptera: Rhinolophidae) on the territory of Serbia. Biol. Serb., 37 (1 - 2): $64-67$

Hothorn, T., Bretz, F., Westfall, P. (2008): Simultaneous inference in general parametric models. Biom. J., 50 (3): 346 - 363. DOI: 10.1002/bimj.200810425

Jones, G., Teeling, E.C. (2006): The evolution of echolocation in bats. Trends Ecol. Evol., 21(3): 149 - 156. DOI: 10.1016/j. tree.2006.01.001

KIRILlov, A.A., KIRILlova, N.Y., VeKHnIIK, V.P. (2012): Trematodes (Trematoda) of bats (Chiroptera) from the Middle Volga Region. Parazitologiya, 46 (5): $384-413$

KIRILLOVA, N.Y., KIRILLOV, A.A., VeKHNIK, V.P. (2007): Trematodes of the brown long-eared bat Plecotus auritus (Chiroptera, Vespertilionidae) from Samarskaya Luka. Plecotus et al., 10: 75 - 81

Kluwak, E., Lazurek, K., Łupicki, D., Popiolek, M., Zaleśny, G. (2013): Helminthofauna of the common noctule Nyctalus noctula (Schreber, 1774) from the Wrocłav area. Ann. Parasitol., 59 (suppl.): 37

KOCHSEDER, G. (1969): Investigations of trematodes and cestodes from bats in Styria. Sitzungsberichten der Österr. Akademie der Wissenschaften, 8: $205-232$

Krasnov, B.R., Bordes, F., Khokhlova, I.S., Morand, S. (2012): Gender-biased parasitism in small mammals: patterns, mechanisms, consequences. Mammalia, 76 (1): 1 - 13. DOI: 10.1515/ mammalia-2011-0108

Lord, J.S., Parker, S., Parker, F., Brooks, D.R. (2012): Gastrointestinal helminths of pipistrelle bats (Pipistrellus pipistrellus/ Pipistrellus pygmaeus) (Chiroptera: Vespertilionidae) of England. Parasitology, 139: 366 - 374. DOI: 10.1017/S0031182011002046 LotZ, J.M., Font, W.F. (1991): The role of positive and negative interspecific associations in the organization of communities of intestinal helminths of bats. Parasitology, 103: 127 - 138. DOI: 10.1017/S0031182000059370

MACY, R.W. (1960): The life cycle of Plagiorchis vespertilionis parorchis. n. ssp., (Trematoda: Plagiorchidae), and observations on the effects of light on the emergence of the cercaria. J. Parasitol., 46: 337 - 345. DOI: $10.2307 / 3275496$

MATSKÁSI, I. (1967): The systematico-faunistical survey of the trematode fauna of Hungarian bats I. Ann. Hist.-Nat. Mus. Natl. Hung., 59: $217-238$

MATSKÁSI, I. (1968): The systematico-faunistical survey of the trematode fauna of Hungarian bats II. Ann. Hist.-Nat. Mus. Natl. Hung., 60: $131-134$

MATSKÁSI, I. (1975): Analysis of host-parasite relationship between bats and flukes in Hungary. Acta. Zool. Acad. Hung., 21: $72-86$
Paunović, M. (1998): New results of bat marking (Mammalia, Chiroptera) in Eastern Serbia. In VI scientific and professional conference on natural resources and environmental protection. Collection of works. Negotin, Serbia, pp. $243-246$

PAUnović, M. (2004): Vernjikica cave - significant winter roost of bats (Mammalia, Chiroptera) in Serbia. Zbornik radova Odbora za kras i speleologiju, 8: 105 - 118

Paunović, M., Karapandža, B., Ivanović, S. (2011): Bats and environmental impact assessment - Methodological guidelines for environmental impact assessment and strategic environmental impact assessment. Belgrade, Wildlife Conservation Society "MUSTELA", $142 p$.

Paunović, M., Pandurska, R., Ivanova, T., Karapandža, B. (2003): Present knowledge of distribution and status of Barbastella barbastellus (Schreber, 1774) (Chiroptera: Vespertilionidae) on the Balkan peninsula. Nyctalus (N. F.), 8 (6): 633 - 638

Pereira, M.J.R., Rebelo, H., Rainho, A., Palmeirim, J.M. (2002): Prey selection by Myotis myotis (Vespertilionidae) in a Mediterranean Region. Acta Chiropterologica, 4 (2): 183 - 193. DOI: 10.3161/001.004.0207

R Core Team. 2015. R: A language and environment for statistical computing. R Foundation for Statistical Computing, Vienna, Austria. http://www.R-project.org/

Rıccl, M. (1995): Report on trematode parasites of bats in Italy. Parassitologia (Rome), 37 (2 - 3): 199 - 214

Rózsa, L., Reiczigel, J., Majoros, G. (2000): Quantifying parasites in samples of hosts. J. Parasitol., 86 (2): 228 - 232. DOI: $10.2307 / 3284760$

Shimalov, V.V., DemyanchiK, M.G., DemyanchiK, V.T. (2011): The helminth fauna of bats (Microchiroptera) in the Republic of Belarus. Vescì Akademiì navuk BSSR. Seryâ biâlagičnyh navuk, 3: 104 110

Siemers, B.M., Greif, S., Borissov, I., Voigt-Heucke, S.L., Voigt, C.C. (2011): Divergent trophic levels in two cryptic sibling bat species. Oecologia, 2011; 166: 69 - 78. DOI: 10.1007/s00442-0111940-1

VAUCHER, C. (1975): On some trematodes parasites of bats and insectivores. Bull. Soc. Neuchatel. Sci. Nat., 98: 17 - 25

VoJTKOVA, L. (1974): Trematoda of amphibians of the CSSR. I. Adult Trematodes. Folia Fac. Sci. Nat. Univ. Purk. Brun., 15: 3 - 131

Warburton, E.M., Pearl, C.A., Vonhof, M.J. (2016): Relationships between host body condition and immunocompetence, not host sex, best predict parasite burden in a bat-helminth system. Parasitol. Res., 115: 2155. DOI: 10.1007/s00436-016-4957-x

ZuK, M., McKeAn, K. (1996): Sex differences in parasite infections: patterns and processes. Int. J. Parasitol., 26 (10), 1009 - 1024. DOI: 10.1016/s0020-7519(96)00086-0 